\title{
Passing needle through stone: A novel surgical technique for porcelain aorta
}

\author{
Mark Helmers, MD, and Pavan Atluri, MD
}

\footnotetext{
From the Division of Cardiovascular Surgery, Department of Surgery, University of Pennsylvania, Philadelphia, Pa.

Disclosures: Authors have nothing to disclose with regard to commercial support.

Received for publication April 17, 2017; accepted for publication April 21, 2017; available ahead of print May 23, 2017.

Address for reprints: Pavan Atluri, MD, Division of Cardiovascular Surgery, Hospital of the University of Pennsylvania, 3400 Spruce St, 6 Silverstein Pavilion, Philadelphia, PA 19104 (E-mail: Pavan.Atluri@uphs.upenn. edu).

J Thorac Cardiovasc Surg 2017; 154:412-3

$0022-5223 / \$ 36.00$

Copyright (c) 2017 by The American Association for Thoracic Surgery

http://dx.doi.org/10.1016/j.jtcvs.2017.04.046
}

Extensive calcification of the ascending aorta or porcelain aorta (PA) poses unique challenges to safe central cannulation, aortic crossclamping, aortotomy, and aortic closure. Although it is rare in the general population, PA has been reported in $7.5 \%$ of patients undergoing evaluation for aortic stenosis. ${ }^{1}$ This population has increased morbidity and mortality with surgical aortic valve replacement. Notably, these patients are subject to perioperative stroke at a rate of $10 \%$.

Several strategies have been described for dealing with the technical challenges that PA portends. Axillary or femoral arterial cannulation strategies prevent direct cannulation of the calcified aorta. ${ }^{3}$ Furthermore, external aortic clamping can be avoided by intraluminal balloon occlusion of the aorta. ${ }^{4}$ Others advocate for aortotomy under hypothermic circulatory arrest, which may allow the identification of a safe aortic clamp site. If no clamp site is identified, aortic valve replacement may be performed under deep hypothermic circulatory arrest. Severely calcified ascending aortas can be replaced with prosthetic grafts, and aortic endarterectomy has also been described.

With the advent of transcatheter aortic valve replacement, an additional weapon has been added to the PA arsenal that does not require cardiopulmonary bypass or aortic clamping. Success rate is high among patients with PA who undergo transcatheter aortic valve replacement, and stroke rate and mortality are similar to those among patients without PA. ${ }^{5}$ Nonetheless, PA can pose technical challenges to transcatheter aortic valve replacement, ${ }^{6}$ and certain clinical circumstances necessitate surgical intervention. It is important that surgeons have the knowledge to be able to manage these difficult scenarios.

In this issue of the Journal, Jacob and colleagues ${ }^{7}$ provide a case report detailing a novel method of homograft reconstruction in a patient with prosthetic aortic valve endocarditis and PA. They describe aortotomy with an oscillating saw with the patient under deep hypothermic circulatory arrest. A hand drill was used to create $0.6-\mathrm{mm}$ holes circumferentially in the calcified distal ascending homograft.

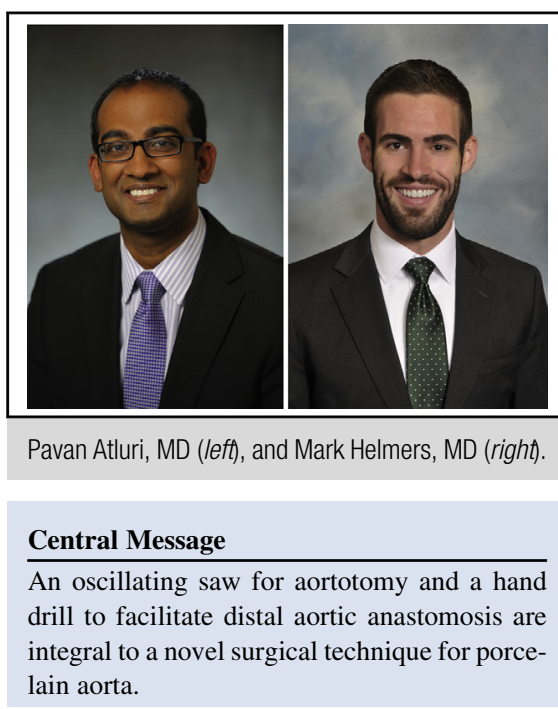

See Article page 409

aorta. This enabled distal anastomosis of a synthetic interposition graft with a 4-0 polypropylene running suture. A 2-cm bovine pericardial patch was secured over this suture line with biologic glue for hemostasis. Clamping of the prosthetic graft then allowed the reinstitution of cardiopulmonary bypass and reconstruction of the aortic root with a

Potential drawbacks of this technique include deposition of calcium debris into the distal aorta. As the lack of neurologic complications in the presented case implies, however, meticulous removal of debris from the open aorta can mitigate stroke risk. In addition, hemostasis at the distal suture line is an inevitable challenge, which Jacob and colleagues ${ }^{7}$ overcame by using a bovine pericardial patch and biologic glue. Anastomotic bleeding could be further addressed with the increasing variety of topical hemostatic agents commercially available. Finally, although the degree of calcification in the arch and descending aorta may have been prohibitive in this case, consideration should be given to performing total arch replacement as an alternative that can be performed with comparable circulatory arrest times. ${ }^{8}$

The described approach prevents the mural thinning, fissuring, and perforation, which may complicate aortic endarterectomy. Furthermore, the use of a prosthetic interposition graft provides a safe cannulation and clamp site for future reoperation. Jacob and colleagues ${ }^{7}$ are to be 
commended for their innovative technique, which should add value to the aortic surgeon's practice.

\section{References}

1. Faggiano P, Frattini S, Zilioli V, Rossi A, Nistri S, Dini FL, et al. Prevalence of comorbidities and associated cardiac diseases in patients with valve aortic stenosis. Potential implications for the decision-making process. Int J Cardiol. 2012;159:94-9.

2. Gillinov AM, Lytle BW, Hoang V, Cosgrove DM, Banbury MK, McCarthy PM, et al. The atherosclerotic aorta at aortic valve replacement: surgical strategies and results. J Thorac Cardiovasc Surg. 2000;120:957-63.

3. Sabik JF, Lytle BW, McCarthy PM, Cosgrove DM. Axillary artery: An alternative site of arterial cannulation for patients with extensive aortic and peripheral vascular disease. J Thorac Cardiovasc Surg. 1995;109:885-90; discussion 890-1.

4. Cosgrove DM. Management of the calcified aorta: an alternative method of occlusion. Ann Thorac Surg. 1983;36:718-9.
5. Rodés-Cabau J, Webb JG, Cheung A, Ye J, Dumont E, Feindel CM, et al. Transcatheter aortic valve implantation for the treatment of severe symptomatic aortic stenosis in patients at very high or prohibitive surgical risk. Acute and late outcomes of the multicenter Canadian experience. J Am Coll Cardiol. 2010;55: 1080-90.

6. Makkar RR, Jilaihawi H, Mack M, Chakravarty T, Cohen DJ, Cheng W, et al Stratification of outcomes after transcatheter aortic valve replacement according to surgical inoperability for technical versus clinical reasons. J Am Coll Cardiol. 2014;63:901-11.

7. Jacob KA, Rozemeijer R, Den Harder AM, Suyker WJ. Aortic homograft replacement in a patient with a porcelain aorta: a case report. J Thorac Cardiovasc Surg. 2017; $154: 409-11$.

8. Gega A, Rizzo JA, Johnson MH, Tranquilli M, Farkas EA, Elefteriades JA Straight deep hypothermic arrest: experience in 394 patients supports its effectiveness as a sole means of brain preservation. Ann Thorac Surg. 2007;84:759-66; discussion 766-7. 